\title{
Sir Francis Galton e os extremos superiores da curva normal
}

\author{
Geraldo Salgado-Neto ${ }^{l}$ \\ Universidade Federal de Santa Maria \\ Aquiléa Salgado 2 \\ Centro Universitário Franciscano \\ In the $19^{\text {th }}$ century, Francis Galton \\ proposed the theory of correlation and \\ regression, the theory of the anticyclone \\ and rediscovered the fingerprints, creating \\ the first system personal identification, \\ was one of the founders of anthropology, \\ but it was with the concept of Eugenics, \\ his greatest contribution that his figure \\ was universally recognized.
}

No século XIX, Francis Galton propôs a teoria da correlação e da regressão, a teoria do anticiclone e redescobriu as impressões digitais, criando o primeiro sistema de identificação pessoal, foi um dos fundadores da antropologia, mas foi com o conceito da Eugenia, sua maior contribuição que sua figura foi mundialmente reconhecida.

Palavras-chave: Antropologia-Biometria -Eugenia-Epistemologia

Keywords: Anthropology - Biometrics Eugenics - Epistemology

\section{Introdução}

Zrancis Galton (1822-1911) é normalmente reconhecido como o primo de C Charles Darwin (1809-1882) ${ }^{4}$. Suas contribuições vão além da sua vasta obra. Sir Francis Galton foi um dos últimos cavaleiros cientistas, era um homem brilhante, foi um dos fundadores da antropologia, meteorologista, matemático, biólogo e inventou os parâmetros estatísticos conhecidos como teoria da regressão e correlação, o primeiro a descrever a teoria do anticiclone, criou em 1873 um dispositivo mecânico para ordenar e analisar dados,

* Sir Francis Galton and the upper extremes of the normal curve

${ }^{1}$ Biólogo e Doutorando em Agronomia. Departamento de Fitotecnia do Centro de Ciências Rurais (CCR), Universidade Federal de Santa Maria. Av. Roraima, 1000, Camobi, Santa Maria, RS, 97105900 (gsalgado@bol.com.br).

${ }^{2}$ Centro Universitário Franciscano, Departamento de Pedagogia, Campus 1, Rua dos Andradas $n^{\circ}$ 1614, Santa Maria, RS, 97010-032 (kilasalgado@ibest.com.br).

${ }^{3}$ Uma visão geral sobre a vida e a obra de Francis Galton é encontrada em IRVINE, P. Sir Francis Galton (1822-1911). Revista de Educação Especial, 20(1), 1986. ALLEN, G. The measure of a Victorian polymath: Pulling together the strands of Francis Galton's legacy to modern biology. Nature, 145(3): 19-20, 2002.

${ }^{4}$ Para uma análise sobre a vida de Charles Darwin: DARWIN, F. (Org.) The life and letters of Charles Darwin, including an autobiographical chapter. Volumes 1, 2 e 3. London: Appleton-CenturyCrofts, 1887 


\section{HUMANAS}

chamado tábua de Galton ou Quincunx (engenhosa máquina, modelo da teoria dos erros, aplicável a muitos fenômenos no campo da Biologia e da Física). Tudo podia ser quantificado por ele, pioneiro da estatística moderna: a eficácia das orações, o aborrecimento, a beleza das mulheres, fenômenos climáticos e a força da seleção natural ${ }^{5}$.

Francis Galton era filho de Samuel Tertius Galton e Anne Violetta; Ele era neto por parte de mãe de Erasmus Darwin (1731-1802) ${ }^{6}$. De crença Quaker era herdeiro de um fabricante de armas e de um banqueiro de Birmingham, onde estudou medicina no General Hospital e posteriormente matemática no King's College de Londres e na Trinity College Cambridge?

Estudante de abordagem decididamente exótica resolveu testar um livro farmacêutico experimentando todos os remédios mencionados na obra em ordem alfabética, desistiu na letra $\mathrm{C}$, vencido pelos efeitos purgativos do óleo de cróton (óleo de rícino). Pouco depois abandonou a medicina para graduar-se em matemática (1844) em Cambridge mesmo envolvendo riscos consideráveis, desistiu da formatura para organizar expedições para explorar territórios desconhecidos no sudoeste, sul e norte da África ${ }^{8}$.

Quando voltou de suas expedições em 1852 estabeleceu-se como explorador entusiasmado e passou a ser descrito como tendo um caso amoroso com a África. No Egito, Galton ficou impressionado com as construções monumentais e as castas de nobres sacerdotes e suas linhagens sagradas de descendência e ancestralidade e as medidas de controle de natalidade dos escravos na construção das cidades de Phithom e PerRamsés éditos de Ramsés I (1292-1290 a.C.) e Ramsés II (1279-1213 a.C.)9.

${ }^{5}$ HENIG, R.M. O Monge no Jardim, o gênio esquecido e redescoberto de Gregor Mendel, o pai da genética. Tradução: Ronaldo Rogério de Biasi. Rio de Janeiro: Rocco, 2001.

${ }^{6}$ Para uma análise sobre a vida de Erasmus Darwin: KING-HELE, D. Doctor of Revolution: the life and genius of Erasmus Darwin. London: Faber \& Faber, 1977. KING-HELE, D. (Ed.). Charles Darwin's The Life of Erasmus Darwin. Cambridge: Cambridge University Press, 2003. KINGHELE, D. (Ed.). The Collected Letters of Erasmus Darwin. Cambridge: Cambridge University Press, 2007.

7 DESMOND, A. \& MOORE, J. Darwin: a vida de um evolucionista atormentado. Tradução: Gustavo Pereira, Hamilton dos Santos e Maria Alice Gelman. São Paulo: Geração Editorial, 1995.

${ }^{8}$ HENIG, R.M. O Monge no jardim, o gênio esquecido e redescoberto de Gregor Mendel, o pai da genética. Tradução: Ronaldo Rogério de Biasi. Rio de Janeiro: Rocco, 2001.

9 GALTON, F. Narrative of an explorer in tropical South Africa. London, New York and Melbourne: Ward, Lock and Co., 1951. ALLEN, G. The measure of a Victorian polymath: Pulling together the strands of Francis Galton's legacy to modern biology. Nature, 145(3): 19-20, 2002. BYNUM, W.F. The childless father of eugenics. Science, 296(1): p. 472, 2002. GARDNER, L. A linhagem do Santo Graal. Tradução: Marcos Malvezzi Leal, São Paulo: Madras Editora LTDA., 2004. KELLER, W. ...E a Bíblia tinha razão. Tradução: João Távora, São Paulo: Círculo do Livro S.A., 1978 (p. 133). Ver o Antigo Testamento:

Então ordenou o Faraó a todo o povo, dizendo: Tudo o que nascer do sexo masculino lançai-o no rio e todas as do sexo feminino guardareis com vida (Ex 1: 22) 


\section{Sir Francis Galton e os extremos superiores da curva normal}

G. Salgado-Neto \& A. Salgado

Estabeleceu relações com a seleção artificial, citada por seu avô Erasmus Darwin em Zoonomia; or, The laws of organic life $(1792)^{10}$.

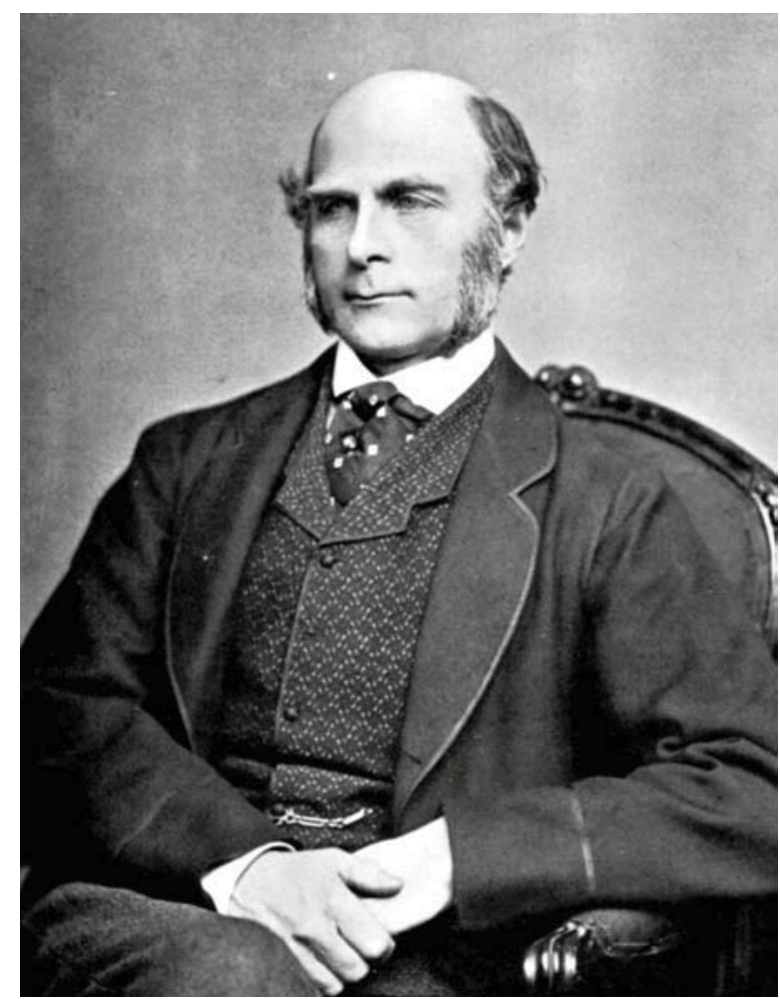

Figura 1

Francis Galton

${ }^{10}$ DARWIN, E. Zoonomia: or, the laws of organic life. London: J. Johnson, 1794, volume 1. SALGADO-NETO, G. Erasmus Darwin e a árvore da vida. Revista Brasileira de História da Ciência, 2(1): 99, 2009.

Secondly, when we think over the great changes introduced into various animals by artificial or accidental cultivation, as in horses, which we have exercised for the different purposes of strength or swiftness, in carrying burthens or in running races; or in dogs, which have been cultivated for strength and courage, as the bulldog; or for acuteness of his sense of smell, as the hound and spaniel; or for the swiftness of his foot, as the greyhound; or for his swimming in the water, or for drawing snow sledges, as the rough-haired dogs of the north; or lastly, as a play-dog for children, as the lap-dog; with the changes of the forms of the cattle, which have been domesticated from the greatest antiquity, as camels, and sheep; which have undergone so total a transformation, that we are now ignorant from what species of wild animals they had their origin (DARWIN, 1794; p. 394). 


\section{HUMANAS}

Secundariamente, quando refletimos sobre as grandes mudanças introduzidas em vários animais através da criação artificial ou acidental, como em cavalos que exercitamos para propósitos diferentes de força ou velocidade ou em cachorros que foram criados para força e coragem como o buldogue; ou para agudez do faro, como o cão de caça; ou para a velocidade, como o galgo; ou com as mudanças das formas do gado que esteve domesticado desde a antiguidade, bem como camelos, e ovelhas; que sofreram uma transformação, tão grande que agora não sabemos de que espécies selvagens eles se originaram (ERASMUS DARWIN, 1794; p. 394).

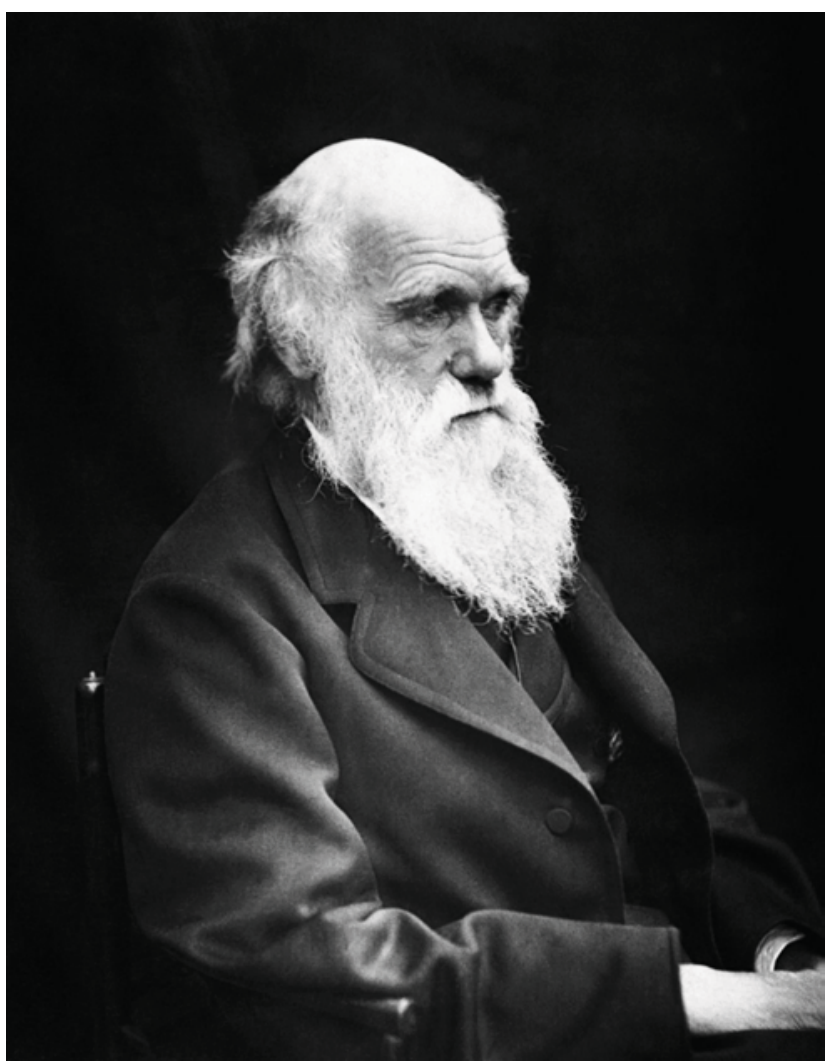

Figura 2

Charles Darwin

Francis Galton observando vasos Egípcios notou impressões digitais (dermatoglifos) e, mais tarde analisando o trabalho de Henry Faulds (1843-1930), 


\section{Sir Francis Galton e os extremos superiores da curva normal}

G. Salgado-Neto \& A. Salgado

tornou a análise das impressões digitais uma ciência chamada datiloscopia, percebeu que o padrão das impressões se mantinha inalterado por toda a vida, classificou as minúcias, como características únicas para cada indivíduo, em um sistema que perdura até os dias de hoje, tornando possível a identificação na Ciência Forense.

Francis Galton escreveu Narrative of an Explorer in Tropical South Africa (1853) descrevendo suas explorações na África, este livro garantiu sua eleição para membro da Royal Geographical Society em 1854, onde foi vicepresidente em 1863. Em 1860 foi eleito fellow da Royal Society (F.R.S.), quando propõem a teoria do anticiclone descrita no livro Metereographica (1863). Francis Galton esteve entre os primeiros a compreender as profundas implicações da evolução para a humanidade e a forma como abria possibilidades para a manipulação científica da própria espécie humana ${ }^{11}$.

Obras de Francis Galton: Narrative of an Explorer in Tropical South Africa (1851); Art of Travel (1855); Metereographica (1863); Hereditary Genius (1869); English men of Science: Their nature and nurture (1874); Inquiries into human faculty (1883); Record of family faculties (1883); Natural Inheritance (1889); Finger Prints (1893); Noteworthy Families (1906) e Memories of my life (1909).

\section{Eugenia}

Influenciado pelo livro On the origin of species de Charles Darwin (1859), ele organizou as principais idéias no livro Hereditary Genius (1869). Na obra Inquiries into human faculty (1883) apresentou o termo Eugenia, que significa "de boa cepa" ou "bem nascer", cunhou o termo "nature and nurture" (Natureza e Criação) em uma versão vitoriana da Eugenia, que já vinha desde Platão. Platão descrevia, em A República, a sociedade humana se aperfeiçoando por processos seletivos (Esparta já praticava a eugenia frente aos recémnascidos 700 a.C.). Galton propôs que o homem pode dirigir a sua evolução, descreveu os resultados dos seus estudos e concluiu, seria perfeitamente possível criar uma raça de homens altamente dotados, por meio de casamentos escolhidos durante gerações consecutivas, sugeriu que a espécie humana poderia ser artificialmente melhorada através de reprodução seletiva ${ }^{12}$.

${ }^{11}$ GALTON, F. Narrative of an Explorer in Tropical South Africa. London, New York and Melbourne: Ward, Lock and Co., 1853. ALLEN, G. The measure of a Victorian polymath: Pulling together the strands of Francis Galton's legacy to modern biology. Nature, 145(3): 19-20, 2002. BYNUM, W.F. The childless father of eugenics. Science, 296(1): 472, 2002.

12 DARWIN, C. On The Origin of Species by Means of Natural Selection. London: John Murray, 1859. GALTON, F. Hereditary Genius: An Inquiry into its Laws and Consequences. London: Macmillan/Fontana, 1869. DIOGENES LAERTIUS. Lives of Eminent Philosophers. In: Loeb Classical Library. English translation by R.D. Hicks. 2 Volumes, London: Harvard University Press, 1959. FERREIRA, R. Darwin, Wallace e a teoria da evolução. São Paulo: Editora UNB, 1990. CLAYES, G. Introducing Francis Galton. Estudos Utópicos, 12(2): 188-190, 2001. 


\section{HUMANAS}

Em Hereditary Genius (1869) demonstrou a lei da herança dos ancestrais ou lei de Galton, usando uma fração para representar a proporção de traços herdados que provinha de cada um dos pais de uma criança, de cada um dos quatro avós, de cada um dos oito bisavós. Segundo a lei, cada pai (designado como $p$ ) fornece ao filho $1 / 2$ do seu complemento genético. Cada avô ( $p p$ ) fornece $1 / 4$ e assim por diante. Desta forma, um traço existente na linhagem de um indivíduo jamais é perdido, mas apenas diluído ${ }^{13}$.

Galton não era cego admirador do primo mais ilustre, muito pelo contrário. Na década de 1860, passou muito tempo tentando ajudar Darwin a compreender, questões de hereditariedade, Darwin dizia que seu primo servia como o mais delicioso dos pudins. Seus experimentos tinham por objetivo demonstrar que a teoria da Pangênese estava completamente errada. Depois de separar coelhos em grupos de cores diferentes e realizar transfusões de sangue de um grupo para o outro, Galton observou, porém, que as transfusões de sangue não tinham nenhum efeito hereditário sobre a cor dos filhotes. A casa de Galton fora invadida por coelhos ${ }^{14}$.

Francis Galton participou do Clube X, loja Maçônica Darwiniana, sua especialidade era talento e caráter hereditários. Ele enfatizava a hereditariedade de cada característica moral ou mental, desde a embriaguez a estupidez, até a sobriedade e a genialidade. Seu trabalho sobre a hereditariedade mental originou a psicometria (Ciência da medição das faculdades mentais). E cita "Os membros mais inteligentes dentro da mesma comunidade terão maior sucesso em relação aos menos inteligentes, e deixarão uma prole numerosa, e essa é uma forma de seleção natural" ${ }^{15}$.

No início da década de 1860 , Galton não tinha conhecimento do trabalho de Gregor Mendel, com a redescoberta dos trabalhos de Mendel em hereditariedade (1900), a Eugenia ganhou ímpeto, acompanhando o surgimento da nova ciência da genética, que nos seus primórdios era ainda mais polêmica ${ }^{16}$.

13 GALTON, F. Hereditary genius: an inquiry into its laws and consequences. Revised edition (1900). New York: D. Appleton, 1869. HENIG, R.M. O monge no jardim, o gênio esquecido e redescoberto de Gregor Mendel, o pai da genética. Tradução: Ronaldo Rogério de Biasi, Rio de Janeiro: Rocco, 2001.

14 DESMOND, A. \& MOORE, J. Darwin: a vida de um evolucionista atormentado. Tradução: Gustavo Pereira, Hamilton dos Santos \& Maria Alice Gelman, São Paulo: Geração Editorial, 1995. HENIG, R.M. O monge no jardim, o gênio esquecido e redescoberto de Gregor Mendel, o pai da genética. Tradução: Ronaldo Rogério de Biasi, Rio de Janeiro: Rocco, 2001.

15 GALTON, F. Hereditary Genius: An Inquiry into its Laws and Consequences. London: Macmillan/Fontana, 1869. GALTON, F. Inquiries into Human Faculty and its Development. New York: AMS Press, 1883. IRVINE, P. Sir Francis Galton (1822-1911). Revista de Educação Especial, 20(1), 1986. DESMOND, A. \& MOORE, J. Darwin: a vida de um evolucionista atormentado. Tradução: Gustavo Pereira, Hamilton dos Santos \& Maria Alice Gelman. São Paulo: Geração Editorial, 1995.

${ }^{16}$ HENIG, R.M. O Monge no Jardim, o gênio esquecido e redescoberto de Gregor Mendel, o pai da genética. Tradução: Ronaldo Rogério de Biasi, Rio de Janeiro: Rocco, 2001. BROOKES, M. Fique por dentro da evolução. Tradução: David Burnie, São Paulo: Cosac \& Nafty Edições, 2001. BROOKES, M. Get a Grip on evolution. London: The Ivy Press Limited, 2001. 


\title{
Sir Francis Galton e os extremos superiores da curva normal
}

G. Salgado-Neto \& A. Salgado

A principal obra de Galton sobre o caráter hereditário da inteligência $\mathrm{He}$ reditary Genius (1869) inclui a antropometria entre seus critérios, mas seu interesse pela medição dos crânios e dos corpos atingiu o nível máximo quando instalou seu Laboratório Antropométrico na Exposição Internacional de Saúde de 1884. Ali pagando uma entrada de três pence, as pessoas podiam passar pela "mesa" linha de montagem de seus testes e medições, e recebiam sua avaliação no final, informações sobre a altura, o peso, a capacidade torácica, a força de impulsão e de compressão, a rapidez de sopro, a audição, a visão e o sentido cromático. O objetivo desse programa de testes em larga escala era definir a gama das capacidades humanas. Galton esperava testar toda a população britânica para determinar o nível exato dos recursos mentais coletivos. Depois da Exposição, manteve o laboratório por seis anos no museu de South Kensington em Londres. O laboratório tornou-se famoso e atraiu muitas pessoas notáveis ${ }^{17}$.

\section{Considerações finais}

Francis Galton levantou dados biométricos e criou técnicas estatísticas: análise de regressão, correlação (co-variação e variância) ainda em uso hoje. Descobriu que as diferenças individuais de muitos traços são distribuídos de acordo com uma curva de distribuição normal. Foi Galton que batizou a curva em forma de sino de "curva normal".

\begin{abstract}
Quanto maior a multidão e maior a anarquia aparente, mais perfeita é sua variação. É a lei suprema da desrazão. Em qualquer lugar onde uma grande amostra de elementos caóticos seja colhida e escalonada segundo a sua magnitude, uma forma de regularidade insuspeitada e das mais belas, prova ter estado latente todo o tempo. Os pontos mais altos da fileira escalonada formam uma curva harmoniosa de proporções invariáveis; e cada elemento, ao ser posicionado, encontra como que um nicho predeterminado, cuidadosamente adaptado para contê-lo (GALTON, 1889).
\end{abstract}

Francis Galton em 1904 fez uma doação ao University College de Londres que permitiu a criação de uma cátedra de Eugenia. O primeiro ocupante do cargo foi Karl Pearson (1857-1936) brilhante matemático, estatístico e advogado de projeção.

${ }^{17}$ GOULD, S.J. A falsa medida do homem. Tradução: Walter Lellis Siqueira, São Paulo: Martins Fontes, 1999. 


\section{HUMANAS}

Em conjunto fundaram (1901) a revista Biometrika e popularizaram o teste do (Qui-quadrado). Segundo Pearson, era necessário um esquema legislativo para que "as raças superiores" suplantassem as "inferiores", que no momento tinham uma taxa de natalidade maior ${ }^{18}$.

Posteriormente, Lewis Terman (1877-1956), campeão da teoria sobre o caráter hereditário da inteligência e introdutor dos testes de QI nos Estados Unidos, desenvolveu um trabalho onde procurava definir e descrever a trajetória vital de pessoas situadas no extremo superior da Escala Stanford-Binet (1917), calculou o QI de Francis Galton em 200, enquanto que o de Charles Darwin era de 135. Darwin abordava com grandes suspeitas os argumentos em favor do caráter hereditário da inteligência, escreveu: "em certo sentido, o senhor Galton transformou um opositor em adepto, porque sempre sustentei que, com exceção dos loucos, os homens pouco diferem entre si quanto ao intelecto, e só se distinguem pelo grau de zelo e constância que exibem em seu trabalho." A resposta de Galton foi quanto à constância no trabalho o caráter, nele se incluindo a capacidade de trabalho, é tão hereditário quanto qualquer outra faculdade ${ }^{19}$

Nas últimas páginas de The Descent of man (1871) Darwin exibe muito explicitamente a sua adesão aos ideais eugenistas: "Os membros de ambos os sexos deviam abster-se de casar em caso de marcada inferioridade do corpo". Ele expressa opiniões pessimistas sobre o futuro da humanidade "Na nossa civilização moderna, a seleção natural já não desempenha qualquer papel e não são os mais aptos os que deixam maior número de descendentes. Os que triunfam não são de modo algum os melhores ou os mais inteligentes e é evidente que a nossa população se renova a cada geração muito mais por obra das classes inferiores ${ }^{20}$.

Herbert Spencer (1820-1903) tentando justificar a competição desenfreada dentro do próprio país escreveu que os pobres deveriam ser deixados de lado, pois eram menos aptos a sobreviver, criou em 1862 a expressão "Sobrevivência ou Persistência dos mais aptos" (Darwin adotou o termo a partir da segunda edição de A origem das espécies). Spencer defendia que os estados não devem entravar o processo natural de seleção biossociológica das elites. As medidas sociais destinadas a "ajudar os pobres" seriam absurdas: a teoria da seleção natural mostrava que os inferiores, menos aptos,

${ }^{18}$ GALTON, F. Natural inheritance. London: MacMillan, 1889. STIGLER, S.M. A história da estatística. Cambridge, Massachusetts: Harvard University Press, 1986. FERREIRA, R. Darwin, Wallace e a teoria da evolução. São Paulo: Editora UNB, 1990.

${ }^{19}$ GALTON, F. Memories of my life. London: Methuen, 1909. TERMAN, L.M. et al., The Stanford Revision extension of the Binet-Simon scale for measuring intelligence. Baltimore: Warwick and York, 1917. GOULD, S.J. A falsa medida do homem. Tradução: Walter Lellis Siqueira, São Paulo: Martins Fontes, 1999 (pp. 69 e 190-95).

${ }^{20}$ DARWIN, C. The descent of man and selection in relation to sex. Londres: John Murray. 1871. BLANC, M. Os herdeiros de Darwin. Tradução: Telma Costa, Teorema: Lisboa. 1990 (p. 150). 


\section{Sir Francis Galton e os extremos superiores da curva normal}

G. Salgado-Neto \& A. Salgado

deviam morrer mais cedo e deixar menos descendentes. A vida na sociedade humana é uma luta pela vida igual a dos animais na natureza. O termo luta pela vida (struggle for life) foi usado em 1776 por Adam Smith (1723-90) e em 1792 por Erasmus Darwin $(1731-1802)^{21}$.

Em 1924 os números e argumentos de Pearson e seus discípulos foram levados a sério por uma maioria de deputados e senadores americanos que aprovaram o sistema de cotas para imigração (Immigration Restriction Act), que garantiria uma permanente predominância de "nórdicos" na população do país. Ao mesmo tempo em vários estados da federação americana foram passadas leis que segregavam os "Débeis Mentais" (Morons). Definidos como todos os adultos que apresentavam uma performance correspondente a 12 anos de idade ou menos no "teste de inteligência" de Stanford-Binet. Em alguns casos os "Débeis Mentais" foram submetidos à esterilização cirúrgica"22.

Charles Darwin foi incontestavelmente um eugenista, mas a o futuro da eugenia foi sinistro. Em seu nome foram esterilizados nos Estados Unidos entre 1900 e 1940 cerca de 36000 pessoas: doentes mentais, transviados e todos os tipos de (marginais, vagabundos) em geral, pessoas que tinham tido o infortúnio de ficarem sem recursos ou internadas em hospitais psiquiátricos por esta ou aquela (má) razão ${ }^{23}$. Incluindo-se o histórico e contínuo extermínio dos povos indígenas americanos.

Hugo Marie De Vries (1848-1935) ao estudar a herança dos caracteres na planta Enótera (Oenothera lamarckiana) descobriu que, embora os padrões de hereditariedade fossem geralmente ordenados e previsíveis, aparecia em certas ocasiões uma nova característica que não tinha sido observada previamente em ambos os tipos parentais. No livro The Mutation Theory (1900) emitiu a hipótese de que esta nova característica consistia na expressão fenotípica de uma alteração em um fator de transmissão hereditário, que mais tarde foi chamado de gene. Além disso, de acordo com sua hipótese, o gene modificado seria então transmitido de modo idêntico ao dos outros genes, denominou esta alteração hereditária de "mutação" e o organismo portador de "Mutante" ${ }^{24}$.

${ }^{21}$ DARWIN, C. On the origin of species by means of natural selection. London: John Murray, 1859 (p. 57). ANDRESKI, S. Herbert Spencer. London: Thomas Nelson and Sons, 1972 (p. 8). BLANC, M. Os herdeiros de Darwin. Tradução: Telma Costa, Teorema: Lisboa, 1990 (p. 148). SMITH, A. An inquiry into the nature and causes of the wealth of nations. Edited by Edwin Cannan. Chicago: University of Chicago Press, 1776/1976. SALGADO-NETO, G. Erasmus Darwin e a árvore da vida. Revista Brasileira de História da Ciência, 2(1), 2009. p. 98.

${ }^{22}$ IRVINE, P. Sir Francis Galton (1822-1911). Revista de Educação Especial, 20(1), 1986. FERREIRA, R. Darwin, Wallace e a teoria da evolução. São Paulo: Editora UNB, 1990 (p. 86). CLAYES, G. Introducing Francis Galton. Estudos Utópicos, 12(2): 188-90, 2001.

${ }^{23}$ BLANC, M. Os herdeiros de Darwin. Tradução: Telma Costa, Teorema: Lisboa, 1990 (p. 150).

${ }^{24}$ DE VRIES, H.M. The mutation theory: Experiments and observation on the origin of species in the vegetable kingdom. Chicago: Open Court Publishing, 1909. 


\section{HUMANAS}

Herman Joseph Muller (1890-1967) acreditava em uma "Elite Genética" e era um eugenista convicto. Em 1939 no início da segunda guerra mundial, reuniu vinte e dois geneticistas para assinarem o "Manifesto dos Geneticistas", em favor do eugenismo, publicado na revista Nature. Nesta declaração, era pedido as mulheres, casadas ou não, que tomassem como ponto de honra procriar os melhores filhos possíveis no plano genético, o que claramente significava que elas deveriam recorrer à inseminação artificial mediante esperma de homens "superiores". Era evidente a relação entre o seu manifesto e as práticas nazistas, em nome da "Raça Superior" estes, já tinham começado, por esta altura a exterminar os deficientes, os doentes mentais, etc., para posteriormente prosseguir com as raças que achavam "inferiores" (judeus e ciganos). Entre os anos 1927 a 1950, Muller, estudou a "transmutação artificial" e as formas de obter mutantes superiores através de indução com raios $X^{25}$.

Medidas Eugênicas, tais como esterilização forçada daqueles julgados débeis mentais, foram tomadas na Alemanha antes e depois da segunda guerra mundial e em uma série de outros países. A Eugenia foi usada para justificar o extermínio de raças consideradas inferiores e alguns dos episódios mais brutais de racismo e genocídio da história recente. Não é exagero dizer que a luta das raças, mencionada por Hitler, que culmina no genocídio dos judeus e dos ciganos deve uma boa parte dos seus fundamentos ao eugenismo e ao racismo científico ${ }^{26}$.

O socialista alemão Alfred Ploetz (1860-1940) se impressiona com as idéias de Francis Galton e cria a Sociedade para Higiene Racial (1880) foi à estréia da eugenia na Alemanha. Hitler foi responsável em pouco mais de doze anos pelo genocídio de quase 12 milhões de pessoas. Com sua autorização, anti-semitas queimaram dezenas de sinagogas, mataram centenas de judeus e levaram mais de 30 mil pessoas para os campos de concentração. $\mathrm{O}$ "programa eutanásia" matou mais de 70 mil doentes mentais e portadores de deficiência. Analisando a filosofia do ódio de Hitler fica claro que a eugenia embasa todos os seus pontos de vista:

A história é uma disputa entre raças, na qual as mais fortes tendem a derrotar as mais fracas. Assim como na evolução das espécies, apenas as raças mais "aptas" sobrevivem; As grandes civilizações da história desapareceram porque deixaram que seu sangue se misturasse ao de outras raças.

${ }^{25}$ MULLER, H.J. Social biology and population improvement. Nature, 144: 521-22, 1939. MULLER, H.J. Artificial transmutation of the gene. Science, 66: 84-85, 1927. BLANC, M. Os herdeiros de Darwin. Tradução: Telma Costa, Teorema: Lisboa, 1990 (p. 92).

${ }^{26}$ HENIG, R.M. O monge no jardim, o gênio esquecido e redescoberto de Gregor Mendel, o pai da genética. Tradução: Ronaldo Rogério de Biasi, Rio de Janeiro: Rocco, 2001 (p. 110). BROOKES, M. Fique por dentro da evolução. Tradução: David Burnie, São Paulo: Cosac \& Nafty Edições, 2001 (p. 181). BROOKES, M. Get a grip on evolution. London: The Ivy Press Limited, 2001. BLANC, M. Os herdeiros de Darwin. Tradução: Telma Costa, Teorema: Lisboa, 1990 (p. 151). 


\title{
Sir Francis Galton e os extremos superiores da curva normal
} G. Salgado-Neto \& A. Salgado

\begin{abstract}
A miscigenação é a causa da decadência das culturas; Judeus são a mais inferior das raças, mas com um incrível instinto de autopreservação. São como parasitas: usam o poder do dinheiro e do capital internacional para se espalhar pelo mundo, infectar e destruir as raças puras; O marxismo é uma estratégia judaica para dominar o mundo. Com ele, os judeus destruíram a Rússia e pretendem "infectar" outros povos, causando sua destruição. Cabe aos arianos, a raça mais superior, eliminar essa ameaça; Para se desenvolver, os alemães precisam de um grande território. As outras raças da Europa devem ser eliminadas para que os arianos possam prosperar sem risco de miscigenação (HITLER, 1924) ${ }^{27}$.
\end{abstract}

A eugenia originou o pensamento que esteve na moda entre os anos de 1920 e 1940. Motivou "Margarete Sanger" Margarete Louise Higgins (18791966) ativista do controle de natalidade e do direito ao aborto legal como método de controle populacional e para evitar nascimentos de crianças com doenças hereditárias graves. Sanger (1932) propôs a criação de um departamento no Congresso Americano para: Manter as portas da imigração fechadas à entrada de certos estrangeiros cuja condição seja reconhecidamente prejudicial à força da raça, tais como retardados mentais e disléxicos, idiotas, lentos, loucos, portadores de sífilis, epiléticos, criminosos, prostitutas profissionais e outros nesta classe barrados pela lei de imigração de 1924. No planejamento Familiar teve as seguintes idéias: "Os habitantes de bairros pobres, devido a sua natureza animal, reproduzem-se como coelhos e logo poderiam ultrapassar os limites de seus bairros, e contaminar então, os melhores elementos da sociedade com doenças e genes inferiores" ${ }^{\prime 28}$.

A riqueza do talento de Francis Galton é comprovada pela variedade de suas pesquisas. Descobriu que as características psicológicas eram herdáveis tais como as características físicas. Certa vez tentou colocar-se no estado mental dos loucos imaginando que todos ou tudo o que via enquanto passeava o estavam espionado: "Ao final do passeio matinal, cada cavalo parecia estar observando-me diretamente, ou, o que era igualmente suspeito, disfarçando sua espionagem ao não lhe prestar, de maneira sofisticada, nenhuma atenção". Galton era um indivíduo extremamente bem dotado cujo talento e temperamento não podiam ficar restritos a uma única disciplina. Basta considerar as áreas de pesquisa a que ele se dedicou, áreas pelas quais os psicólogos mais tarde se interessaram:

${ }^{27}$ HITLER, A. Mein Kampf. Mariner Books, 1924. BROWNING, C.R. The path to genocide: essays on launching the Final Solution. Cambridge University Press, 1992.

${ }^{28}$ SANGER, M. A plan for peace. Birth Control Review, 1932 (p. 106). 


\section{HUMANAS}

adaptação, hereditariedade versus ambiente, comparação de espécies, desenvolvimento infantil, método do questionário, técnicas estatísticas, diferenças individuais, testes mentais. Pelo alcance dos seus interesses e métodos, influenciou Charles Darwin na elaboração do livro The Expression of the Emotions in Man and Animals (1872) e toda a posterior psicologia americana ${ }^{29}$.

No final do livro On the Origin of Species, Charles Darwin (1859) escreveu: "Entrevejo, num futuro remoto, caminhos abertos a pesquisas muito mais importantes ainda... isto é, sobre a aquisição necessariamente progressiva de todas as faculdades e de todas as aptidões mentais, o que lançará uma nova luz sobre a origem do homem e sua história". Desde então, o entendimento do que é inteligência evoluiu muito, absorvendo vários conceitos. Lamentavelmente, porém decorridos um século e meio, ainda não há uma teoria formal sobre a origem da inteligência nos seres vivos. O termo "inteligência" é um dos maiores equívocos da filosofia e da psicologia atuais. Hoje o conceito parece significar entendimento, intelecto, conjunto de funções cognitivas, razão e capacidade de resolver problemas. O termo latino "intelligentia" significava penetrar dentro das coisas, captar a sua intimidade, discernir ou entender a essência, descrevia uma atividade passiva, sem desempenhar um papel ativo. Modernamente, o ser inteligente deve exibir um comportamento ativo, tentando resolver problemas com base em sua memória ou sendo criativo (imaginação), a partir da análise dos eventos já ocorridos durante a sua existência, aumentando assim as suas chances de adaptação e sobrevivência ${ }^{30}$.

Analisando de forma evolutiva a eugenia (seleção artificial) opõe-se à seleção natural. A seleção artificial é a manipulação genética feita pelo homem. Nessa seleção, o homem seleciona os genes que considera serem os melhores. Mas o que é considerado melhor para o homem pode não ser o melhor meio adaptativo. O problema da seleção artificial é que não há como padronizar o melhor gene, pois de região para região as condições ambientais variam, tal é o caráter circunstancial e localizado do processo evolutivo. A evolução por seleção natural não possui direção ou trajetória. Qualquer forma de padronização diminui o valor adaptativo das espécies a longo prazo. Se escolhermos sempre os "melhores" para sobreviver, estamos reduzindo a variabilidade genética da população como um todo e a longo prazo diminuindo a capacidade de adaptação da espécie humana às variações do ambiente, contribuindo assim para a espécie rumar em direção à extinção, quando uma espécie esta em vias de extinção apenas os mais criativos e engenhosos sobrevivem,

${ }^{29}$ SCHULTZ, S.E. \& SCHULTZ, D.P. História da psicologia moderna. São Paulo: Cultrix, 1998. DARWIN, C. A expressão das emoções no homem e nos animais - Introdução de Konrad Lorenz. Tradução: Leon de Souza Lobo Garcia. São Paulo: Companhia das Letras. 1872/2000 (p. 346).

${ }^{30}$ DARWIN, C. On the origin of species by means of natural selection. London: John Murray, 1859 (p. 374). MORAIS, M. Logos - Enciclopédia Luso-Brasileira de Filosofia. Lisboa e São Paulo: Editorial Verbo, 1990 (p. 1447). 


\section{Sir Francis Galton e os extremos superiores da curva normal}

G. Salgado-Neto \& A. Salgado

à medida que a população diminui as aptidões daqueles que sobrevivem aumentam, dados genéticos mostram que o homem moderno sofreu um gargalo demográfico no início da sua diferenciação o que provavelmente reduziu o número dos nossos ancestrais a menos de 10.000 pessoas $^{31}$.

Charles Darwin era primo em primeiro grau de sua esposa Emma Wedgwood (1808-96), filhos de pais aparentados em primeiro grau correm riscos de cerca de $4 \%$ de ter alguma doença gênica, relacionada à deficiência mental. Sem contar a idade avançada de Emma (tinha quase 49 anos quando deu à luz em dezembro de 1856), o que representava cerca de mais 4\% de risco de a criança nascer com Síndrome de Down. O bebê Charles Waring Darwin nasceu sem o pleno domínio de suas faculdades mentais, nunca aprendeu a andar ou falar, morreu em 1858 de difteria. No livro The Descent of man (1871) Charles Darwin se refere a casos de degeneração e reversão ao tipo selvagem, como atavismos e efeitos de cruzamentos, chegou a esboçar a "Lei da Reversão", mas por evidentes questões pessoais evitou discutir com mais detalhes o assunto. Em 1866, em uma conferência no Hospital de Londres, John Langdon Down (1828-96) apresentava como características da degeneração da espécie a "Reversão Mongolóide", uma classificação dos tipos aberrantes e deficientes mentais, em bases étnicas, foi chamada também de "Idiotia Mongolóide" e posteriormente batizada de Síndrome de Down.

$$
\begin{aligned}
& \text { O aspecto da criança é tal que é difícil perceber que } \\
& \text { seja filho de europeus, mas dada a freqüência com } \\
& \text { que estas características se apresentam, não pode } \\
& \text { haver dúvida de que estes traços étnicos são pro- } \\
& \text { duto de degeneração (DOWN, 1866; p. 261) }
\end{aligned}
$$

Cesare Lombroso (1835-1909) famoso médico italiano. Em 1887 lançou a teoria da criminalidade inata e a criação da disciplina chamada antropologia criminal. Onde o criminoso nato era um ser atávico que podia ser identificado por sua anatomia peculiar "características físicas simiescas". Assim relacionou traços físicos com propensão ao crime, afirmando que alguns bandidos nascem para o mal. Nunca abandonou a idéia de que o crime tinha raízes biológicas e que os criminosos são símios vivendo entre nós, indivíduos marcados pelos estigmas anatômicos do atavismo, acabou sentenciando que todos os criminosos natos padeciam de epilepsia em menor ou maior grau.

${ }^{31}$ FORD, E.B. Genetics and adaptation. Biology Institute, Edward Arnold, 1976. LAHR, M.M. The evolution of modern human diversity. Cambridge: Cambridge University Press, 1996.

${ }^{32}$ KEYNES, R. Darwin, his daughter \& human evolution. London: River-head Books, 2001 (p. 247). DARWIN, C. On the origin of species by means of natural selection. London: John Murray, 1859. DOWN, J.L. Observations on an ethnic classification of idiots. Clin. Lec. \& Reports, London Hospital, 1866 (pp. 259-62) - “A publicação da descrição da Síndrome de Down em 1866 levou Charles Darwin a se corresponder com John Langdon Down sobre os casos de degeneração da espécie humana" (Down, 1866; p. 247). 


\section{HUMANAS}

A sua teoria impôs a milhares de epiléticos que se tornassem alvo dos programas eugênicos por que interpretou a enfermidade como um sinal de degeneração moral. Sabemos que os estigmas de Lombroso chegaram a ser importantes critérios de juízo em muitos processos criminais e de perícia em concursos públicos, milhares sofreram e ainda sofrem condenações injustas e preconceito em suas vidas por serem consideradas "inaptas." O preconceito pode ser tão antigo quanto o registro da história humana, mas a sua justificação biológica impôs o fardo adicional da inferioridade intrínseca aos grupos menos favorecidos e descartou a sua possibilidade de se redimir através da conversão ou da assimilação ${ }^{33}$.

A Eugenia foi diretamente relacionada com objetivos de manipulação da espécie humana e da criação de uma raça superior. Neste sentido, Galton foi, por diversas vezes representado como reacionário e anti-humanista, apesar de ter sido mal interpretado, nunca pretendeu a criação de uma elite superior, mas antes a melhoria das capacidades inatas da população como um todo. Apenas usou o termo Eugenia para expressar a possibilidade de aprimoramento da raça humana por meio de cruzamentos genéticos premeditados. Foi abençoado com uma vida longa e feliz, não teve filhos, nomeado Cavaleiro da Coroa Britânica em 1909. Sir Francis Galton foi elevado e agraciado pela Royal Society em 1910 com a sua distinção máxima (coroa de louros) a Copley Medal (Medalha Copley) e morreu em Surrey dia 17 de Janeiro de 1911.

\section{Agradecimentos}

Nossos sinceros agradecimentos a Associação de Pais e Amigos dos Excepcionais (APAE). Nós entendemos que a inclusão social é um instrumento extremamente importante para o fim do preconceito e a melhoria da qualidade de vida e da dignidade das pessoas com deficiência.

\section{Referências bibliográficas}

ALLEN, G. The measure of a Victorian polymath: Pulling together the strands of Francis Galton's legacy to modern biology. Nature, 145(3): 19-20, 2002.

ANDRESKI, S. Herbert Spencer. London: Thomas Nelson and Sons, 1972

BLANC, M. Os herdeiros de Darwin. Tradução: Telma Costa, Teorema: Lisboa. 1990

${ }^{33}$ LOMBROSO, C. L'homme criminel. Paris, F. Alcan, 1887. GOULD, S.J. A falsa medida do homem. Tradução: Valter Lellis Siqueira. São Paulo: Martins Fontes, 1999 (pp. 18 e 133). 


\section{Sir Francis Galton e os extremos superiores da curva normal G. Salgado-Neto \& A. Salgado}

BROOKES, M. Fique por dentro da evolução. Tradução: David Burnie, São Paulo: Cosac \& Nafty Edições, 2001.

BROOKES, M. Get a Grip on evolution. London: The Ivy Press Limited, 2001.

BYNUM, W.F. The childless father of eugenics. Science, 296(1): 472, 2002.

CLAYES, G. Introducing Francis Galton. Estudos Utópicos, 12(2): 188-90, 2001.

DARWIN, C. A expressão das emoções no homem e nos animais - Introdução de Konrad Lorenz. Tradução: Leon de Souza Lobo Garcia. São Paulo: Companhia das Letras. 1872/2000 (p. 346).

DARWIN, C. On The origin of species by means of natural selection. London: John Murray, 1859. GALTON, F. Hereditary Genius: An Inquiry into its Laws and Consequences. London: Macmillan/Fontana, 1869.

DARWIN, C. On the origin of species by means of natural selection. London: John Murray, 1859

DARWIN, C. The descent of man and selection in relation to sex. Londres: John Murray. 1871.

DARWIN, E. Zoonomia: or, the laws of organic life. London: J. Johnson, 1794, v. 1.

DARWIN, F. (Org.) The life and letters of Charles Darwin, including an autobiographical chapter. Volumes 1, 2 e 3. London: Appleton-Century-Crofts, 1887.

DE VRIES, H.M. The mutation theory: experiments and observation on the origin of species in the vegetable kingdom. Chicago: Open Court Publishing, 1909.

DESMOND, A. \& MOORE, J. Darwin: a vida de um evolucionista atormentado. Tradução: Gustavo Pereira, Hamilton dos Santos e Maria Alice Gelman. São Paulo: Geração Editorial, 1995.

DIOGENES LAERTIUS. Lives of eminent philosophers. In: Loeb Classical Library. English translation by R.D. Hicks. 2 Volumes, London: Harvard University Press, 1959.

DOWN, J.L. Observations on an ethnic classification of idiots. Clin. Lec. \& Reports, London Hospital, 1866 (pp. 259-62) - "A publicação da descrição da Síndrome de Down em 1866 levou Charles Darwin a se corresponder com John Langdon Down sobre os casos de degeneração da espécie humana" (Down, 1866; p. 247).

FERREIRA, R. Darwin, Wallace e a teoria da evolução. São Paulo: UNB, 1990. 


\section{HUMANAS}

FORD, E.B. Genetics and adaptation. Biology Institute, Edward Arnold, 1976.

GALTON, F. Hereditary genius: an inquiry into its laws and consequences. Revised edition (1900). New York: D. Appleton, 1869.

GALTON, F. Hereditary Genius: an inquiry into its laws and consequences. London: Macmillan/Fontana, 1869.

GALTON, F. Inquiries into human faculty and its development. New York: AMS Press, 1883.

GALTON, F. Memories of my life. London: Methuen, 1909.

GALTON, F. Narrative of an explorer in tropical South Africa. London, New York and Melbourne: Ward, Lock and Co., 1951.

GALTON, F. Narrative of an Explorer in Tropical South Africa. London, New York and Melbourne: Ward, Lock and Co., 1853.

GALTON, F. Natural inheritance. London: MacMillan, 1889.

GARDNER, L. A Linhagem do Santo Graal. Tradução: Marcos Malvezzi Leal, São Paulo: Madras Editora LTDA., 2004.

GOULD, S.J. A falsa medida do homem. Tradução: Walter Lellis Siqueira, São Paulo: Martins Fontes, 1999.

HENIG, R.M. O monge no jardim, o gênio esquecido e redescoberto de Gregor Mendel, o pai da genética. Tradução: Ronaldo Rogério de Biasi. Rio de Janeiro: Rocco, 2001.

HITLER, A. Mein Kampf. Mariner Books, 1924.

BROWNING, C.R. The path to genocide: essays on launching the Final Solution. Cambridge University Press, 1992.

IRVINE, P. Sir Francis Galton (1822-1911). Revista de Educação Especial, 20(1), 1986.

KELLER, W. ...E a Bíblia tinha razão. Tradução: João Távora, São Paulo: Círculo do Livro S.A., 1978 (p. 133). Ver o Antigo Testamento

KEYNES, R. Darwin, his daughter \& human evolution. London: Riverhead Books, 2001 (p. 247).

KING-HELE, D. (Ed.). Charles Darwin's the life of Erasmus Darwin. Cambridge: Cambridge University Press, 2003. 


\section{Sir Francis Galton e os extremos superiores da curva normal G. Salgado-Neto \& A. Salgado}

KING-HELE, D. (Ed.). The collected letters of Erasmus Darwin. Cambridge: Cambridge University Press, 2007.

KING-HELE, D. Doctor of Revolution: the life and genius of Erasmus Darwin. London: Faber \& Faber, 1977.

LAHR, M.M. The evolution of modern human diversity. Cambridge: Cambridge University Press, 1996.

LOMBROSO, C. L'homme criminel. Paris, F. Alcan, 1887. GOULD, S.J. A falsa medida do homem. Tradução: Valter Lellis Siqueira. São Paulo: Martins Fontes, 1999 (pp. 18 e 133).

MORAIS, M. Logos - Enciclopédia Luso-Brasileira de Filosofia. Lisboa e São Paulo: Editorial Verbo, 1990 (p. 1447).

MULLER, H.J. Artificial transmutation of the gene. Science, 66: 84-85, 1927.

MULLER, H.J. Social biology and population improvement. Nature, 144: 521-22, 1939.

SALGADO-NETO, G. Erasmus Darwin e a árvore da vida. Revista Brasileira de História da Ciência, 2(1): 99, 2009.

SANGER, M. A plan for peace. Birth Control Review, 1932 (p. 106).

SCHULTZ, S.E. \& SCHULTZ, D.P. História da psicologia moderna. São Paulo: Cultrix, 1998.

SMITH, A. An inquiry into the nature and causes of the wealth of nations. Edited by Edwin Cannan. Chicago: University of Chicago Press, 1776/1976.

STIGLER, S.M. A história da estatística. Cambridge, Massachusetts: Harvard University Press, 1986.

TERMAN, L.M. et al., The Stanford Revision extension of the Binet-Simon scale for measuring intelligence. Baltimore: Warwick and York, 1917. 